ERJ

Engineering Research Journal

Faculty of Engineering

Menoufiya University

\title{
Study on Vertical Air Curtains for Multi-deck Viewer Refrigerated Display
}

\author{
Mostafa A. Abdel-Baky* Shedeed H. Shams El-Dein* Tareq E. Shalma** \\ *Staff members, Dept. of Mech. Power Engineering, Faculty of Engineering \\ Minoufiya University, Shebin El-kom, Egypt \\ **Production Manager, Fricool Refrigeration Industry Company
}

\begin{abstract}
Air curtains are devices used in refrigerated display cabinets and the entrance of air conditioned spaces is aimed to reduce the breakthrough of heat, moisture and contaminants between the conditioned environment and the surrounding ambient, consequently reducing energy costs. The main objective of the present work is to study the parameter affecting the performance of air curtains used in viewer refrigerators using one and two air curtains at different ambient conditions, in order to reduce the air infiltration and consequently the energy consumption. The results of one and two air curtains are compared, where two air curtains are more effective than one air curtain

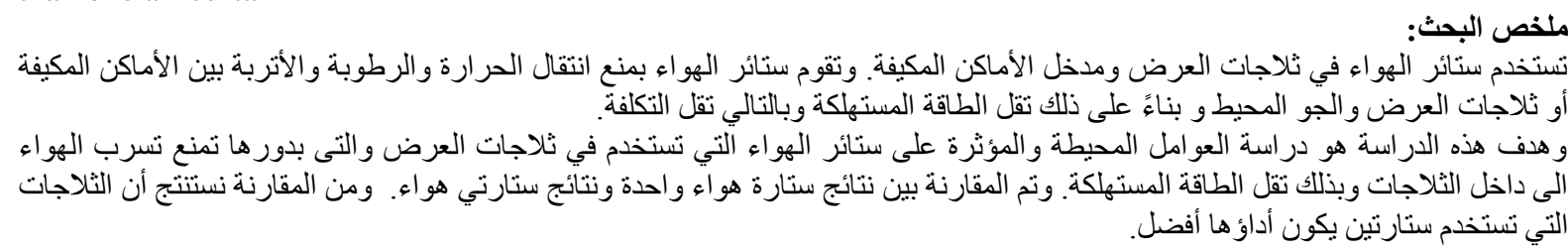

Keywords: Air curtain, Vertical refrigerated multi-deck, Plane free jet, Heat transfer through air curtains.

\section{Introduction}

Display cabinets are designed to preserve the storage temperature of food. They are not able of reducing the temperature of products if they are too warm when loaded. Air curtains are devices used in refrigerated display cabinets, and the entrance of air conditioned spaces to reduce the breakthrough of heat, moisture and contaminants between the display cabinets and the surrounding ambient, which led to reduce energy costs. Forced air circulation inside display cabinets is preferable, because it is more effective in temperature distribution inside display cabinets, thus enabling the correct operation of the display cabinet. Display cabinets may use one air curtain, two air curtains or three air curtains.

In the majority of multi-deck retail display cabinets, the evaporator is located in the base of the cabinet and a fan withdraws air through it to be cooled then it passes in a duct at the rear of the cabinet. Air exits from the duct through holes or slots in the cabinet rear grille and also through a slot or a honeycomb grille placed at the front of the cabinet canopy, termed the discharge grille.

The performance of general-purpose air curtains depends on a number of parameters which include [1]:

1- The width and length of the air jet;
2- The initial jet velocity;

3- The jet initial turbulence;

4- The position and dimensions of the air return grille; and

5- Conditions of air on both sides of the air curtain.

All of the above parameters are functions of the design and application of the air curtain. In most cases, the prediction of their performance in standard applications relies on curves supplied by the manufacturer. A number of mathematical models have been developed to aid the design and performance prediction of air curtains. Major contributions to the work include those of Hetsroni [2], Hayes [3] and Van [4].

Hetsroni [2] worked with a recirculatory type air curtain and developed an entrainment spill model to calculate the heat transfer through the air curtain. His simulation results were taken to predict the heat transfer with an accuracy of $20 \%$ compared to measurements in the laboratory. Hayes [3] investigated heated non-recirculated air curtains. He developed a model to predict the total heat transfer across the air curtain and used it to investigate the effect of various design parameters such as jet angles, initial velocities and jet temperatures on heat transfer. Similar to Hetsroni's model, Hayes' model assumed Low initial turbulence intensities, less than $1 \%$, and uniform initial 
velocity profiles. Following to Hayes' work, Van [4] developed a model to investigate the influence of the initial turbulence intensity of heat and mass transfer through an air curtain. The experimental and modeling results showed that initial turbulence intensity would have little effect on the heat and mass transfer through long air curtains.

The model developed by Van [4] was subsequently applied by Howell and Adams [5] to investigate heat and moisture transfers across air curtains employed on refrigerated display cabinets. Tests carried out on two different air curtain lengths at different room and display cabinet conditions showed differences between computed and measured heat transfers of between $0.7 \%$ and $26.5 \%$. Reasons for the errors were not reported but measurement errors would have a significant effect on the overall accuracy of the results.

Cortella et al. [6] worked with a finite element method to analyze the distribution of velocity and temperature in refrigerated display cabinet. They found that when the air velocity at the inner curtain was lower than outer one, multiple air curtains led to a lower air spillage from air curtain to the floor.

Navaz et al. [7] used both experimental and numerical methods to predict the parameters those have significant effects on the amount of warm air in an open refrigerated display case. They found that the turbulence intensity, the mean velocity profile at the discharge air grill and the Reynolds number are main factors those are responsible for the amount of warm air in a display case. The results showed that lowering Reynolds number of the air curtain reduces the entrainment (warm) rate.

$\mathrm{Yu}$ et al. [8] established a modified two-fluid turbulence model to simulate the flow and heat transfer characteristics of air curtains in an open vertical display cabinet. The air exiting the back panel, the inner air curtain and the outer air curtain are taken as the first fluid and described with the standard k- $\varepsilon$ turbulence model. The air outside the display cabinet is considered as the second fluid and calculated by the laminar model. The results of comparisons between the simulated temperatures and the experimental ones showed that the modified two-fluid model (MTF) could give better agreement with the measurements than $\mathrm{k}-\varepsilon$ and two original two-fluid models.

Agaro et al. [9] simulated the air flow pattern and the temperature distribution in a frozen food vertical display cabinet. At first the choice of solver parameters has been investigated in a $2 \mathrm{D}$ modelisation. 3D simulations have been performed to predict the effects of the cabinet length, the warm air curtain temperature and of longitudinal ambient air movement on the performance of air curtain. The results indicate that, in short cabinets, 3D secondary vortices at the side walls provide the most important mechanism for hot air entrainment. Comparison with experimental resulted showed that a $2 \mathrm{D}$ simulation is totally inadequate for such configurations while 3D computations predict refrigeration power within engineering accuracy.

Up to date, most researches on refrigerated display cabinets were focused on computational fluid dynamics (CFD) simulation and experimental studies mainly concentrated on the effects of air supply velocity and initial turbulent intensity on the development of an air jet for one air curtain or two air curtains separately [10-12].

The main objective of the present study is to get the lowest temperature in vertical multi-deck open cabinet using two air curtains at different ambient temperature and relative humidity by reducing the external air infiltration and consequently reduction of energy consumption and comparing the results with a single air curtain

\section{Description of flow patterns}

The flow patterns of one and two parallel air curtains are shown schematically in Figs. (1) and (2). For one air curtain, flow is divided into three regions, potential core region, transition region and developed region, see Fig. (1). The characteristic of the potential core region is that the centerline velocity is almost constant and equal to the outlet velocity $u_{0}$. Also the turbulence intensity is constant. The length of this zone is about 5:8 times the jet thickness $b_{o}[1]$.

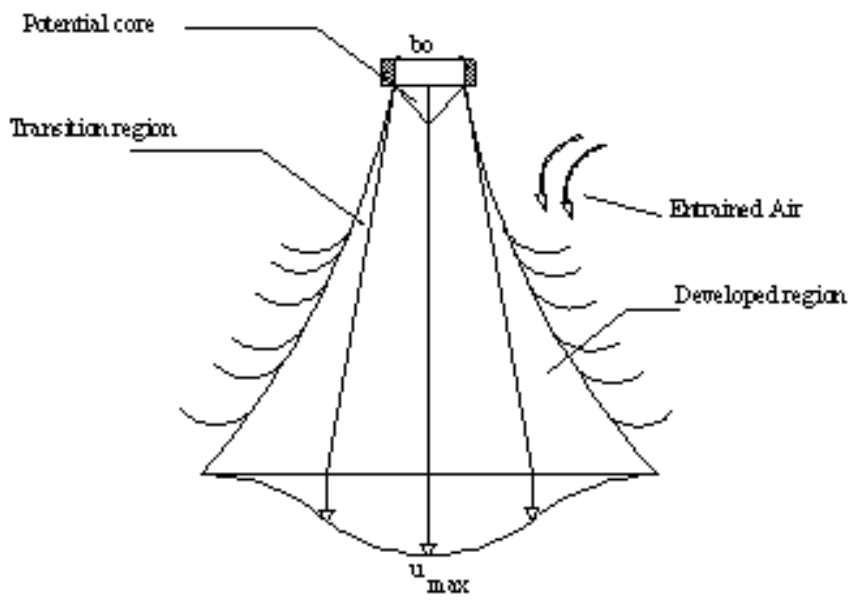

Fig. (1) Flow patterns of one air curtain

As a result of the combined entrainment between the two jets of air curtains, a sub-atmospheric pressure region is formed close to curtain outlet. The sub-atmospheric pressure causes individual jets, which known as the converging region, see Fig. (2). The two potential cores of the two air curtains combine at merging point where the centerline velocity is zero. This point is called merging point. Downstream from the merging point, in the merging region, the two air jets continue to interact with each other and the centerline velocity increases until it reaches a maximum value at the combined point. Downstream from the combined point, the two air jets combine together to be like a single free jet flow. 
1. A steady three-dimensional model is employed regardless of the display cabinet length.

2. The standard k- $\varepsilon$ two equations model $(\mathrm{k}-\varepsilon)$ is selected to simulate the turbulent fluid.

3. Radiation heat transfer is not taken into consideration.

4. The Boussinesq hypothesis is selected due to the density varying with aerostatic pressure.

\subsection{Boussinesq approximation}

The basis of this approximation is that there are flows in which the temperature varies little, and therefore the density varies little. Thus the variation in density is neglected everywhere except in the buoyancy term. Natural convection was considered by using the Boussinesq approximation in which density was treated as a constant value in all solved equations except for the buoyancy term in the momentum equations which was treated as: $\left(\rho_{\mathrm{o}}-\rho\right) \mathrm{g}=$ $\rho_{\mathrm{o}} \beta\left(\mathrm{T}-\mathrm{T}_{\mathrm{o}}\right)$, where $\rho_{\mathrm{o}}$ and $T_{\mathrm{o}}$ are the reference density and temperature respectively and $\beta=1 / T_{0}$ is the thermal expansion coefficient

\subsection{Buoyancy}

The purpose of the air curtain is to provide a momentum force to resist the buoyant force caused by the difference in density and temperature between the air inside and outside of the cabinet. The buoyant force, therefore requires modeling to predict the system. The air in this model is treated as an ideal gas where its density is linked to the temperature by the ideal gas law:

$\mathrm{P}=\rho \mathrm{RT}$

A numerically simpler approach is to use the Boussinesq approximation:

$\left(\rho_{\mathrm{o}}-\rho\right) g=\rho_{\mathrm{o}} \beta\left(\mathrm{T}-\mathrm{T}_{\mathrm{o}}\right)$

This model uses a constant density fluid. The Boussinesq approximation is suitable only if density variations are small.

\subsection{Boundary conditions}

The velocities and the temperatures of the air curtains are given in Table 2. The inlet turbulent kinetic energy $k_{\text {inlet }}$ and the energy dissipation rate $\varepsilon_{\text {inlet }}$ of the air curtain are derived from the following relationship:

$$
k_{\text {inlet }}=0.01 u_{o}^{2}
$$

$\varepsilon_{\text {inlet }}=0.01 k_{\text {inlet }}^{3 / 2} / b_{o}$

Where $u_{o}$ is the inlet velocity of the air curtain and $b_{o}$ is the width of the air curtain (either the inner air curtain or the outer air curtain). Non-slip boundary condition (zero velocity) is selected at the solid surfaces.

The following table (2) gives the values under a typical display case operation condition.
Table (2) Principal parameters of the display case

\begin{tabular}{|l|l|}
\hline Parameters & Values \\
\hline Display case width $\mathrm{W}(\mathrm{m})$ & 0.61 \\
\hline Display case height $\mathrm{H}(\mathrm{m})$ & 0.45 \\
\hline Inner air curtain width $\mathrm{b}_{\mathrm{o}, \text { in }}(\mathrm{m})$ & 0.03 \\
\hline Outer air curtain width $\mathrm{b}_{\mathrm{o}, \text { out }}(\mathrm{m})$ & 0.03 \\
\hline Ambient temperature $\mathrm{T}_{\mathrm{a}}\left({ }^{\circ} \mathrm{C}\right)$ & 20 \\
\hline Ambient relative humidity $(\%)$ & 45 \\
\hline Outer air curtain velocity $\mathrm{u}_{\mathrm{o}, \text { out }}(\mathrm{m} / \mathrm{s})$ & 0.69 \\
\hline Inner air curtain velocity $\mathrm{u}_{\mathrm{o}, \text { in }}(\mathrm{m} / \mathrm{s})$ & 0.69 \\
\hline Outer air curtain temperature $\mathrm{T}_{\text {out }}\left({ }^{\circ} \mathrm{C}\right)$ & 4.4 \\
\hline Inner air curtain temperature $\mathrm{T}_{\text {in }}\left({ }^{\circ} \mathrm{C}\right)$ & 11 \\
\hline
\end{tabular}

The computer program, FLUENT 6.2 was used to solve the time-independent (steady state) conservation equations together with the standard $\mathrm{k}-\varepsilon$ model, and the corresponding boundary conditions. The numerical solution grid divided the space of the cold room into discretized computational cells of the order of 500,000 tetrahedral cells. Solution convergence criteria, was applied at each iteration and ensured the summations of normalized residuals were less than $10^{-4}$ for flow, $10^{-4}$ for $\mathrm{k}$ and $\varepsilon$, and $10^{-6}$ for energy.

\section{Experimental Setup}

The apparatus on which the experimental work has been conducted was built in heat engine laboratory, Faculty of Engineering at Shebine El-Kom, Egypt. It was a single deck, vertical viewer refrigerator that shown in Fig. (3). The unit consists of a vertical cabin supplied with a refrigeration unit. The cabinet was made of steel - polyurethane panel. The outer and inner sides of the cabin were made of $1 \mathrm{~mm}$ wall thickness steel sheet. The polyurethane insulation used was of $50 \mathrm{~mm}$ thickness and it has thermal conductivity of $0.025 \mathrm{~W} / \mathrm{m} . \mathrm{K}$.

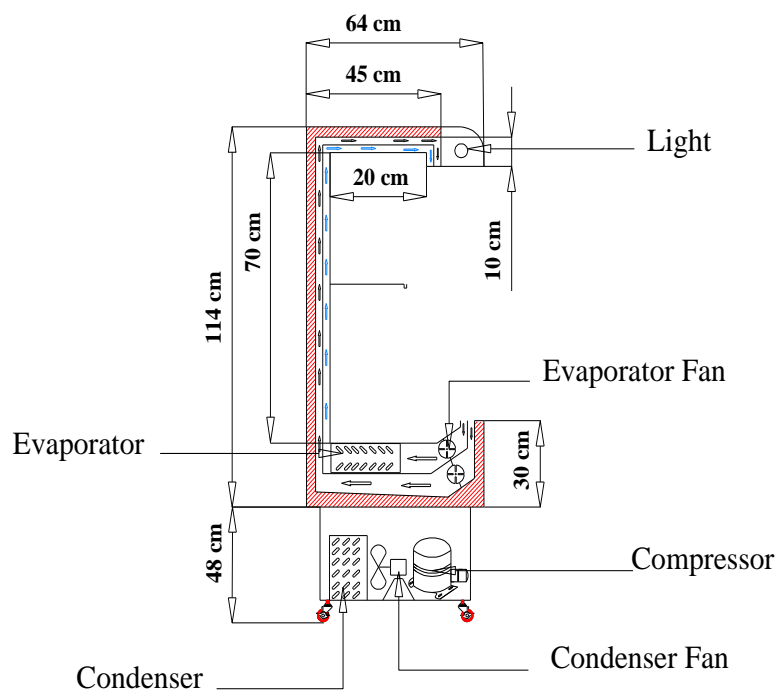

Fig. (3) Test section

The refrigeration unit consists of an evaporator, a compressor $550 \mathrm{~W}$, a condenser and an expansion device. The outer dimension of the display cabinet is $1.2 \mathrm{~m}, 0.63 \mathrm{~m}$ 
and $0.72 \mathrm{~m}$ long. Two fans were installed to provide the required air in the cabinet, one of them was fixed before the evaporator in first duct while the last one was fixed inside the second duct. The air curtain width were 13 and $5 \mathrm{~cm}$ for both one and two air curtains. The back panel width and top ceiling gap were $50 \mathrm{~mm}$.

The test section was installed inside an isolated room of $2.5 \times 1.5 \times 2 \mathrm{~m}$. The room was made of steel-Polyurethane panel with $5 \mathrm{~cm}$ insulation. It was supplied with a split air conditioning unit of $1.125 \mathrm{~kW}$ electric power consumption, a humidifier, electric heater and relative humidity and temperature controls and to maintain the inside room at the required various test conditions as defined by the ISO test standard.

In order to measure the temperature distribution inside and outside the display cabinet, thermocouples of $\mathrm{K}$ type were distributed inside it as shown in Fig. (4). The measuring range of that type is $-50^{\circ} \mathrm{C}$ to $200^{\circ} \mathrm{C}$. The thermocouples were chicked for damage before installation. The output signals of the thermocouples were transferred to a digital temperature indicator set. The relative humidity was measured by digital hegrostate at the same lacations of temperature measurement. A cup anemometer was also used to measure the air flow velocity at the same locations.
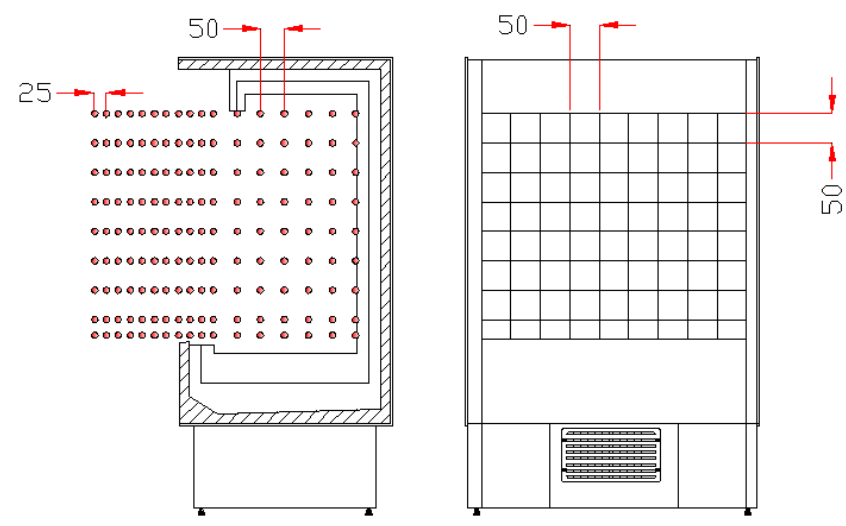

Fig. (4) Positions of measuring the velocity, temperature and relative humidity of air.

\section{5- Results and Discussion}

Figure (5) indicates a comparison of predicted velocity distribution $\mathrm{u} / \mathrm{u}_{\mathrm{o}}$ between the experimental work and four numerical models, they are; $\mathrm{k}-\varepsilon$ model and $\mathrm{k}-\Omega$ model, laminar model and Reynolds stress model (RSM). Laminar model is less accurate because the flow may be more turbulent in this region. The other three of the turbulence models predicted this velocity gradient much better. The theory of turbulent jets suggests that an initial region of the jet exists before the turbulence region (laminar region due to honeycomb). As the air curtain develops downstream of the outlet, the centerline velocity decays and the pattern of the air flow spreads. It then follows that small eddies in the flow direction into larger ones increasing the length scale and resulting in a higher Reynolds number. It seems, therefore, that the flow is becoming more turbulent. Both k- $\varepsilon$ and $\mathrm{k}-\Omega$ models provided the best prediction of the velocity profile at mid of air curtains. $\mathrm{k}-\varepsilon$ model is chosen for this present work as it is more accurate and it was used in most previous researches.

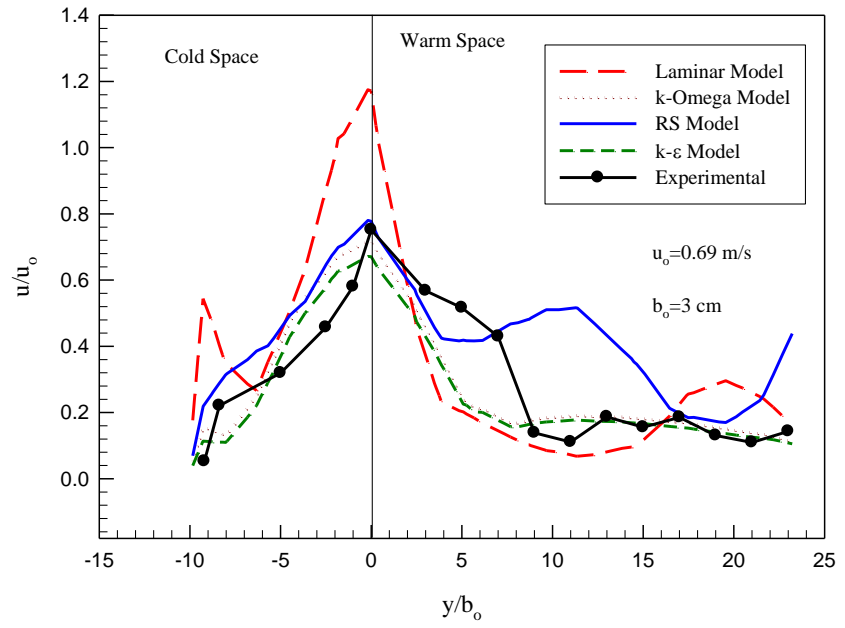

Fig. (5) Comparison of velocity profiles at $\mathrm{x} / \mathrm{b}_{\mathrm{o}}=12$, two air curtains.

\subsection{Velocity distribution for two air curtain}

Figure (6) gives the contours of velocity in both refrigerator and test room. For vertical multi-deck cabinet considered here, the cold air is blown through two linear diffusers placed in front of the canopy, to form the two air curtains. Each linear diffuser is supplied by a separate fan, where a honeycomb panel ensures a uniform air distribution and an accurate control of the jet velocities.

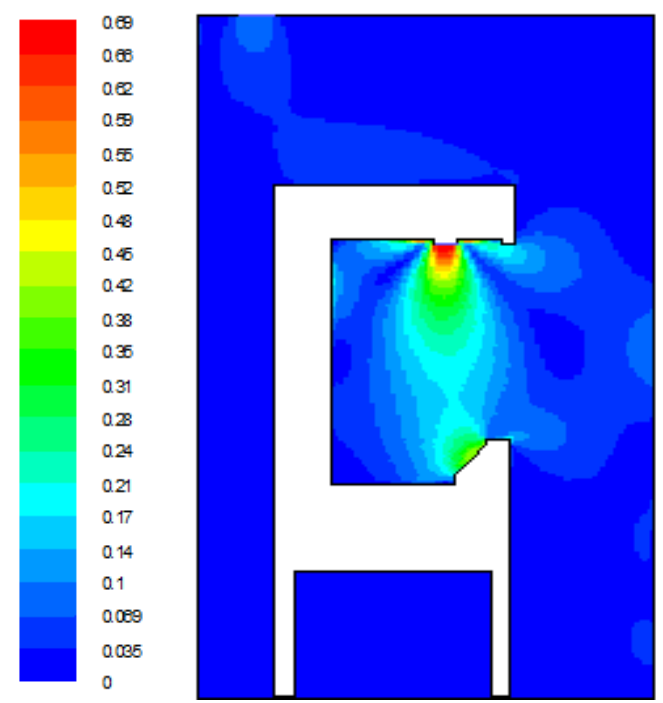

$\mathrm{u}[\mathrm{m} / \mathrm{s}]$

Fig. (6) Contours of velocity of air through air jets 


\subsection{Comparison between the air velocity distributions through one and two air curtains}

Figures (7), (8) and (9) represent the comparison of velocity profiles at $x / b_{0}=6,12$ and 20 respectively, for the case of one air curtain and two air curtains. From the comparison of the results, it is found that at $\mathrm{x} / \mathrm{b}_{\mathrm{o}}=6$ the velocity profile at the case of two air curtains are greater than the velocity profile for one air curtain. This is because of the air entrainment at outer air curtain which spills out of the refrigerator. At the same time the inner air curtain spills inside the refrigerator, which lead to keep the inside temperature cool and constant. Consequently, the velocity is decreased slightly. At one air curtain the air entrainment occurred where part of the air curtain spills out the refrigerator and the other part combined with some of outside air is induced inside the refrigerator, which means increasing the temperature inside the refrigerator and the velocity decreases due to air entrainment.

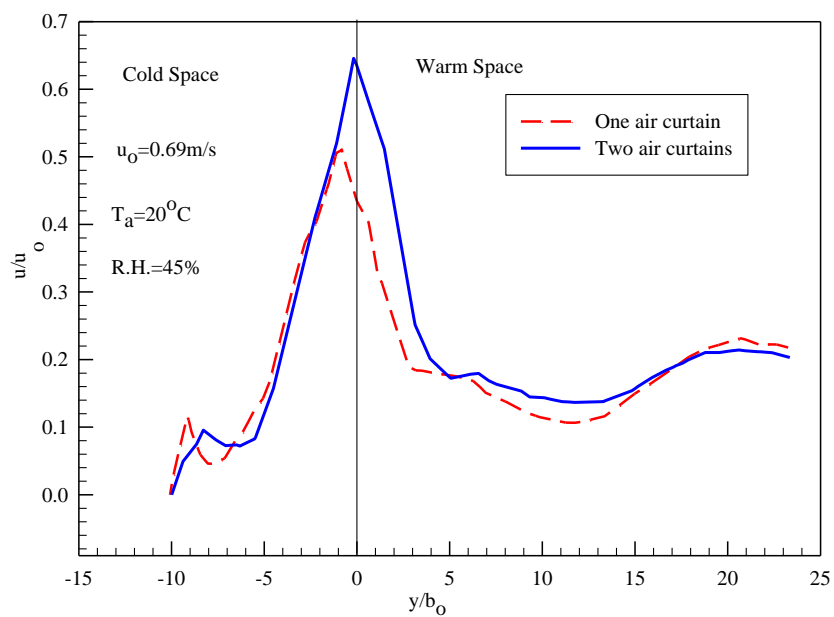

Fig. (7) Comparison of velocities distributions of one and two air curtains at $\mathrm{x} / \mathrm{b}_{\mathrm{o}}=6$.

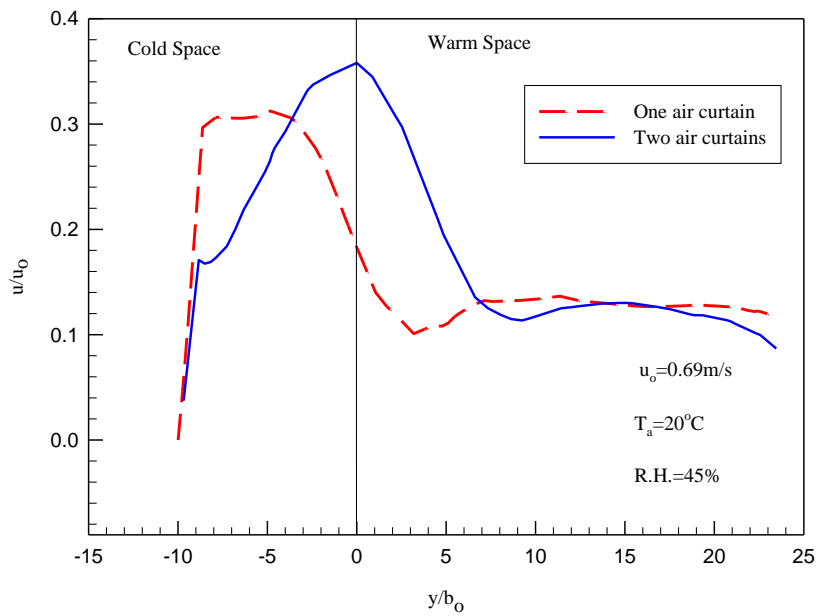

Fig. (8) Comparison of velocities distributions of one and two air curtains at $\mathrm{x} / \mathrm{b}_{\mathrm{o}}=12$.
From Fig. (9) it can be seen that at $y / b_{o}$ equal to about 6 , where outside air is combined with air curtain there is circulation due to the fan suction.

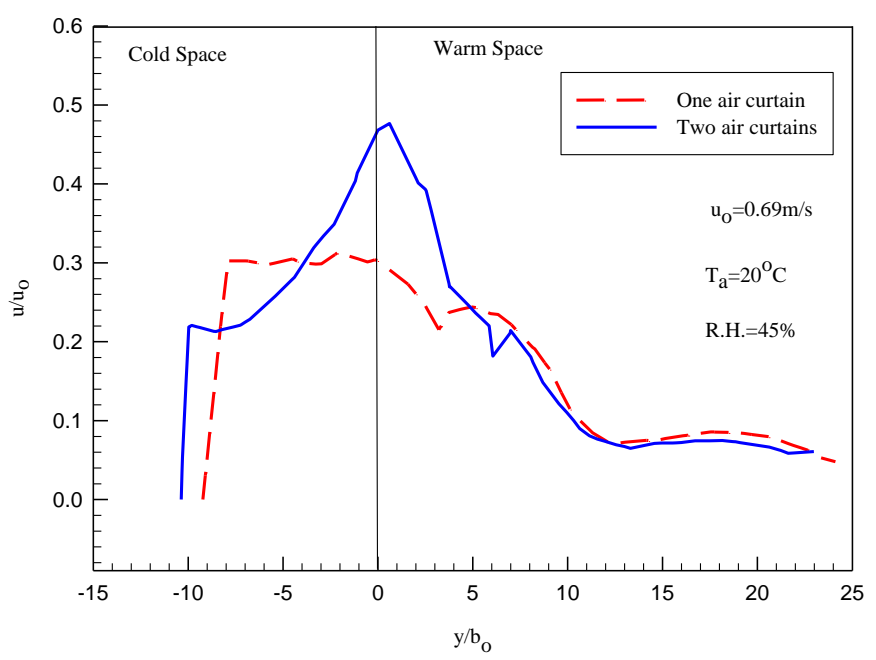

Fig. (9) Comparison of velocities distributions of one and two air curtains at $\mathrm{x} / \mathrm{b}_{\mathrm{o}}=22$.

\subsection{Comparison of the temperature Distribution in cases of one and two air curtains}

Figures (10), (11) and (12) illustrate the temperature distribution for one and two air curtains. It can be seen that in the display cabinet of using the two air curtains the temperatures inside the fridge is cooler than that inside the fridge using one air curtain as mentioned previously. Also, it can be seen that as $x / b_{o}$ is increasing the value of $T / T_{o}$ decreases in the fridge with two air curtains. At $y / b_{0}=6$, $\mathrm{T} / \mathrm{T}_{\mathrm{o}}$ in both one air curtain and two air curtains is the same due to the velocities of air curtains at maximum value and uniform so that the air entrainment does not start. On the other hand, it can be seen also that as $y / b_{o}$ increases, $T / T_{o}$ increases due to same previous reason.

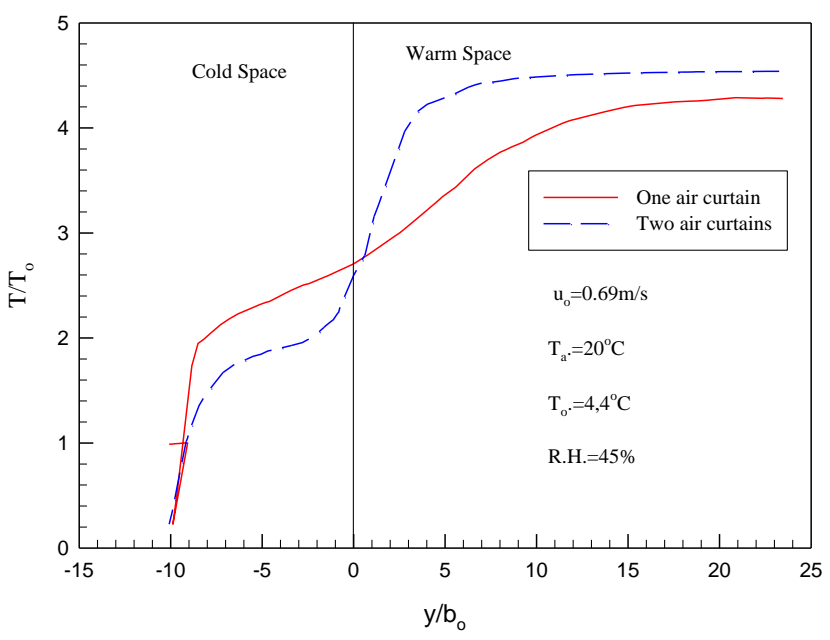

Fig. (10) Comparison of air temperatures distributions of one and two air curtains at $\mathrm{x} / \mathrm{b}_{\mathrm{o}}=3$ 


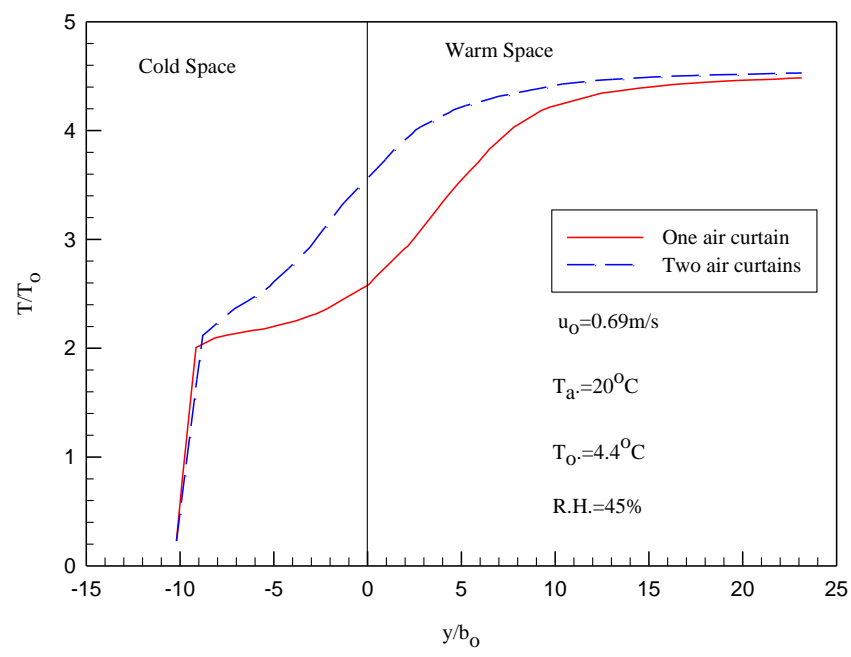

Fig. (11) Comparison of air temperatures distributions of one and two air curtains at $\mathrm{x} / \mathrm{b}_{\mathrm{o}}=12$

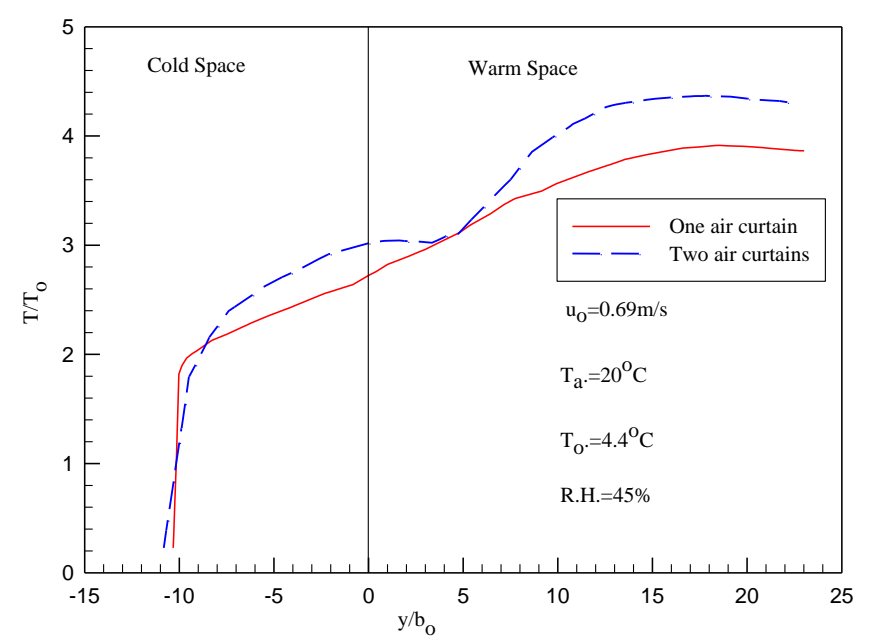

Fig. (12) Comparison of air temperatures distributions of one and two air curtains at $\mathrm{x} / \mathrm{b}_{\mathrm{o}}=20$

\subsection{Comparison between humidity ratio distributions through one and two air curtains}

The simulations were carried out with air curtain temperature of $4.4^{\circ} \mathrm{C}$ which discharge from outlet and ambient temperature $20^{\circ} \mathrm{C}$ and relative humidity $45 \%$ at different $x / b_{o}$ and $y / b_{0}$. The following Figures illustrated the influence of ambient conditions on humidity ratio through one and two air curtains.

As shown in the following Figs (13), (14) and (15), it can be seen that the effect of ambient conditions on humidity ratio inside the fridge. It was shown that the humidity ratio inside the fridge is lower in the case of using two air curtains is lower than that in the fridge uses one air curtain. Also, it can be seen that, as $y / b_{o}$ increases the humidity ratio $\omega / \omega_{0}$ is increased for both one and two air curtains.

As shown from Fig. (13) it can be seen that $\omega / \omega_{0}$ in the case of one air curtain near the back of the fridge is lower than $\omega / \omega_{0}$ in the case of two air curtain, this is because the temperature through duct at $\mathrm{x} / \mathrm{bo}=3$ in the case of two air curtains is higher than one air curtain. And as $\mathrm{x} / \mathrm{bo}$ increases the temperature in the duct will decrease (at $\mathrm{y} / \mathrm{bo}=-10)$.

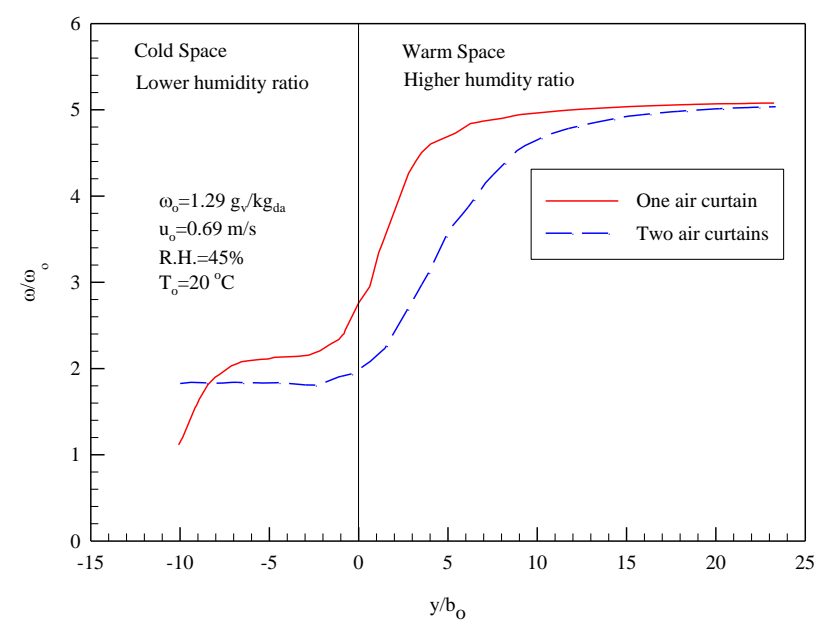

Fig. (13) Comparison of humidity ratio distributions of one and two air curtains at $\mathrm{x} / \mathrm{b}_{\mathrm{o}}=6$

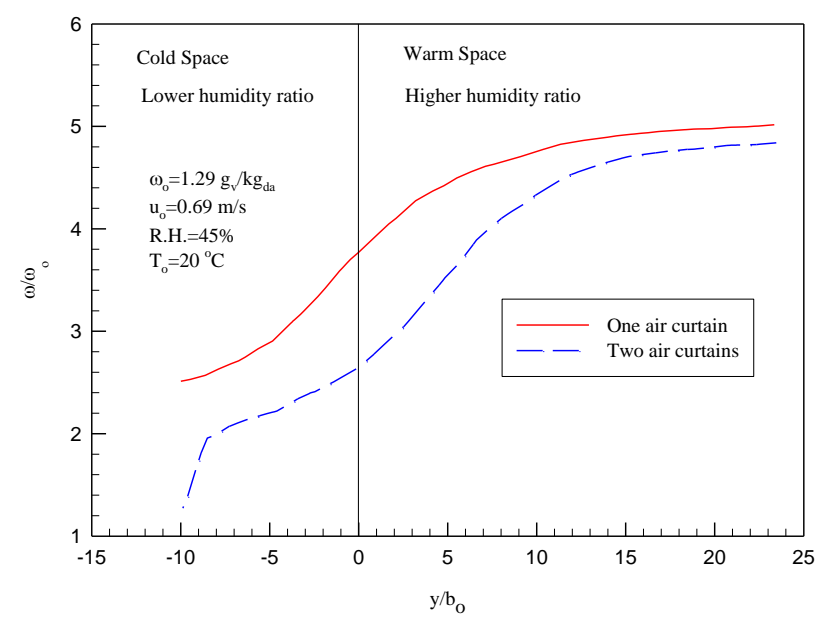

Fig. (14) Comparison of humidity ratio distributions of one and two air curtains at $\mathrm{x} / \mathrm{b}_{\mathrm{o}}=12$

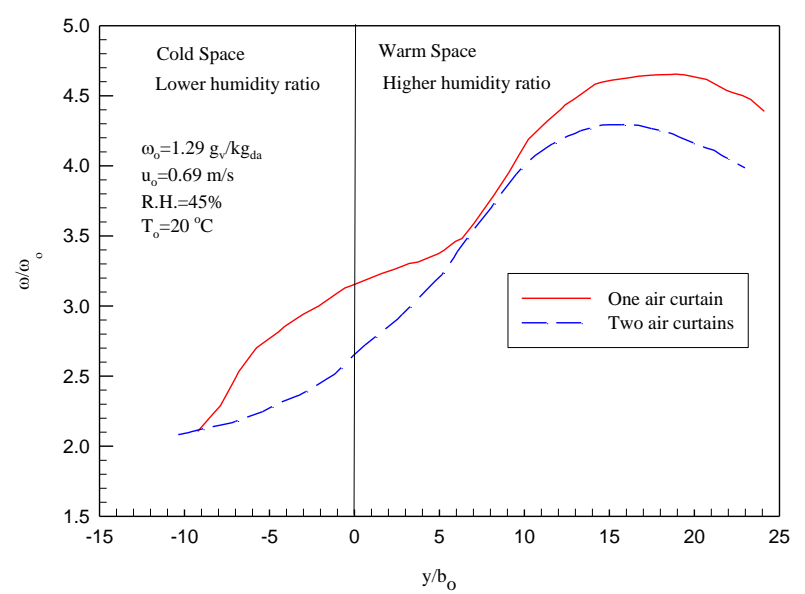

Fig. (15) Comparison of humidity ratio distributions of one and two air curtains at $\mathrm{x} / \mathrm{b}_{\mathrm{o}}=22$ 


\section{Heat transfer calculation model}

The entrainment-spill model is similar to that used by Hetsroni [2] for the recirculatory type air curtain. Hetsroni proposed that, the main heat transfer mechanism is due to heated air from the room being entrained into the jet, and then it is cooled, and spilled back into the room again at a lower temperature. The heat transfer rate can be calculated from the velocity and temperature distributions at a jet cross-section just before the impingement point as shown in Fig. (16). The heat transfer model depends on the effect of temperature and humidity ratio differences between the two sides of the air curtain. As shown in Figs. (1) and (2), the two air curtains can be dealed as one air curtain.

The flow pattern of the air curtain can be divided into two parts. The first part is the secondary air entrained from each side (cold space and warm space). This part causes the divergence of the air curtain jet and it spills back at the floor level (with different conditions) to the side from which it comes. Therefore, it causes heat transfer to this side, see Fig. (16). The second part is the primary air that is used in the air curtain outlet which may come from one side of the curtain (cold space and warm space). This air comes with certain conditions ( $\mathrm{T}$ and HR) and used in curtain. These conditions will be changed when it spills back at the floor level to the side from which it comes. This change will cause certain heat load on this side.

The heat transfer rate can be calculated from the velocity and temperature distributions at a jet cross-section just before the impingement point shown in Fig. (16).

The sensible heat transfer rate for air curtain side, depending on the temperature of this side $\mathrm{T}_{\text {side }}$ (cold space or warm space), and can be given by [2]:

$\dot{Q}_{s}=\dot{Q}_{s(\operatorname{Sec})}+\lambda \dot{Q}_{s(\operatorname{Pr} i m)}$

Where $\lambda$ is a factor equal to 1 in case of heat transfer calculation for the side from which the primary air comes and it is equal to ( 0 ) if the heat transfer calculation is for the other side.

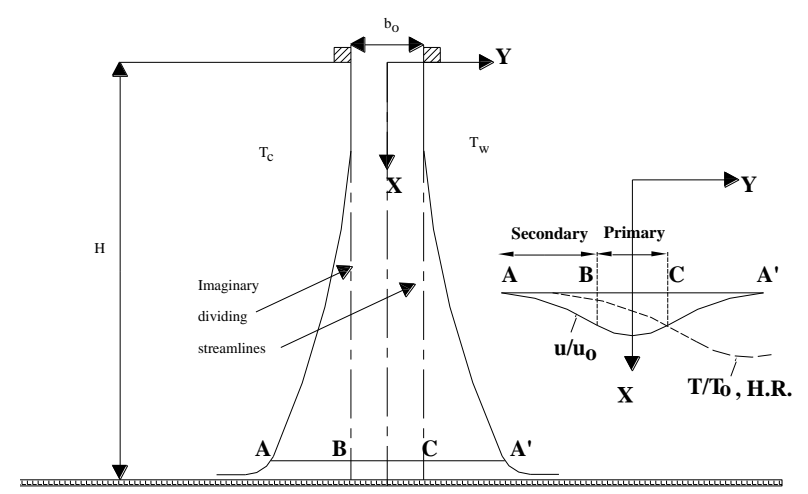

Fig. ('6) Description of heat transfer model

$$
\begin{aligned}
\dot{Q}_{s}= & \dot{m}_{a(\operatorname{Sec})} \mathrm{C}_{\mathrm{p}}\left(\mathrm{T}_{\text {side }}-\mathrm{T}(\mathrm{Y})_{\mathrm{Sec}}\right)+ \\
& \lambda \dot{m}_{a(\operatorname{Pr} i m)} \mathrm{C}_{\mathrm{p}}\left(\mathrm{T}_{\mathrm{o}}-\mathrm{T}(\mathrm{Y})_{\text {Prim }}\right)
\end{aligned}
$$

Where $T_{o}$ is the outlet temperature of the air curtain.

$$
\begin{aligned}
\dot{Q}_{s} & =W \int_{y_{A}}^{y_{b}} \rho C_{p} u(y)\left(T_{\text {side }}-T(y)_{\mathrm{sec}}\right) d y \\
& +\lambda W \int_{y_{A}}^{y_{b}} \rho C_{p} u(y)\left(T_{o}-T(y)_{\text {prim }}\right) d y
\end{aligned}
$$

(Just before the impingement point at $\mathrm{X}=\mathrm{H}$ )

Equation (8) represents the difference between the dry air enthalpy of the entrained air into the jet from air certain side and enthalpy of dry air on this side. Also the difference between the enthalpy of primary air used in the curtain, that spilled back into this side again just before the impingement point, with the enthalpy of dry air on this side. Two assumptions are involved in this equation:

1. The length of the entrainment zone, measured along the axis of the jet, is $\mathrm{H}$, regardless of the amount of deflection of the jet. This means that the location of section AA' of the jet shown in Fig. (16) will always lie slightly above the floor because of the curvature of the jet.

2. The velocity and temperature distributions for the air spilling back into the space are the same as those between points $\mathrm{A}$ and $\mathrm{A}^{\prime}$, Fig. (16).

From convection heat transfer, a heat transfer coefficient, $h$, is defined by

$Q_{s}=\mathrm{h}(\mathrm{H} . \mathrm{W})\left(\mathrm{T}_{\mathrm{w}}-\mathrm{T}_{\mathrm{c}}\right)$

If the specific heat is assumed constant and an average value is used for the air density, applying the mass conservation (at outlet of air curtain at level B-C) and stream function definition at $\mathrm{Y}_{\mathrm{C}}=\mathrm{Y}_{\mathrm{B}}$ : it will obtain $\psi_{\mathrm{C}}=0.5$, $\psi_{\mathrm{B}}=-0.5$.

$$
\frac{N u}{\operatorname{Re} . \operatorname{Pr}}=\int_{\mp \psi_{A}}^{\mp 0.5}(\theta) d \psi+\lambda \int_{-0.5}^{0.5}(\theta) d \psi
$$

The negative sign is used for the secondary part for calculating the sensible heat transfer for the left side, and the positive sign is used for right side in Fig. (16).

By solving Equations (9) and (10) using the compound Simpson method of integration. The values of $(\mathrm{Nu} / \mathrm{RePr})$ for different values of opening height $\mathrm{H}$ or $\left(\mathrm{H} / \mathrm{b}_{\mathrm{o}}\right)$ can be calculated. From Fig. (17) it is shown that the ratio $\mathrm{Nu} / \mathrm{Re}$.Pr is greater in primary air, and increases as $\mathrm{H} / \mathrm{b}_{\mathrm{o}}$ increases due to entrained air from warm space section C-A' Fig.(16). Although the ratio $\mathrm{Nu} / \mathrm{Re} \mathrm{Pr}$ in secondary air 
increases with $\mathrm{H} / \mathrm{b}_{\mathrm{o}}$, but it is lower than in primary air. This is because of the amount of entrained air from cold space section A-B Fig. (16).

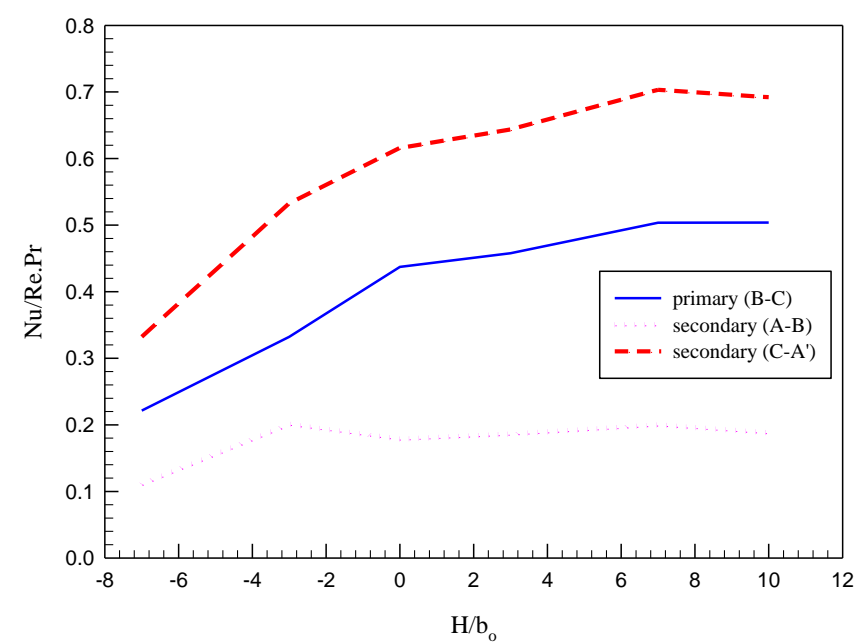

Fig. (17) Variation of $(\mathrm{Nu} / \mathrm{Re} . \mathrm{Pr})$ with $\mathrm{H} / \mathrm{b}_{\mathrm{o}}$

The results obtained could be fitted and the following equation is obtained:

$$
\begin{aligned}
\frac{N u}{R e \cdot P r} & =0.6069+0.0256 \frac{H}{b_{o}} \\
& -0.00175\left(\frac{H}{b_{o}}\right)^{2}
\end{aligned}
$$

From $\mathrm{Nu} / \mathrm{Re} \mathrm{Pr}$, the value of heat convection coefficient could be obtain as following:

$$
h=\frac{\rho_{a v} u_{o} b_{o} C_{p}}{H} \frac{N u}{\operatorname{Re} \cdot \operatorname{Pr}}
$$

The values of $\rho_{\mathrm{av}}$ and $\mathrm{C}_{\mathrm{p}}$ almost constant and equal to 1.15 $\mathrm{kg} / \mathrm{m}^{3}$ and $1.005 \mathrm{KJ} / \mathrm{kg} . \mathrm{K}$ respectively. The obtained value could be substituted in Eq. (13);

$Q_{s}=h A \Delta T$

Then:

$$
\begin{aligned}
\dot{Q}_{s}= & \pm \rho_{a v} C_{p} u_{o} b_{o} W\left(T_{w}-T_{c}\right) \times[0.6069 \\
& \left.+0.0256 \frac{H}{b_{o}}-0.00175\left(\frac{H}{b_{o}}\right)^{2}\right]
\end{aligned}
$$

The positive sign is used for the sensible heat added to the cold side and the negative sign is used for the sensible heat loss from the warm side.

\subsection{Latent Heat Transfer Calculations}

The latent heat transfer rate can be calculated from the velocity and humidity ratio distributions at a jet crosssection just before the impingement point see Fig. (16). Where the latent heat transfer rate is given by:

$\dot{Q}_{L}=\dot{Q}_{L(\operatorname{Sec})}+\lambda \dot{Q}_{L(\mathrm{Pr} i m)}$

The rate of mass convection can be expressed as:

$$
\begin{aligned}
& \dot{m}_{\text {conv }}=h_{\text {mass }} \rho A\left(\omega_{\text {higher }}-\omega_{\text {lower }}\right) \\
& \dot{Q}_{L}=\dot{m}_{\text {conv }} i
\end{aligned}
$$

and enthalpy of moist air can be expressed as [11]:

$$
\begin{array}{rl}
\dot{Q}_{s}=2502+1.84 \mathrm{~T} & W \int_{y_{A}}^{y_{b}} \operatorname{\rho iu}\left(\omega_{\text {side }}-\omega(y)_{\mathrm{sec}}\right) d y \\
& +\lambda W \int_{y_{A}}^{y_{b}} \operatorname{\rho iu}\left(\omega_{o}-\omega(y)_{\text {prim }}\right) d y
\end{array}
$$

(Just before the impingement point) at $\mathrm{X}=\mathrm{H}$,

Appling the mass conservation (at outlet of air curtain and level (B-C) and stream function definition at $\mathrm{Y}_{\mathrm{C}}=\mathrm{Y}_{\mathrm{B}}: \omega_{\text {higher }}=\omega_{\text {lower }}$ it will obtain $\psi_{\mathrm{C}}=0.5, \psi_{\mathrm{B}}=-0.5$.

$$
\begin{aligned}
\dot{Q}_{L} & =\mathrm{Wu}_{\mathrm{o}} \mathrm{b}_{\mathrm{o}} \mathrm{i} \rho_{\mathrm{av}}\left[\int_{\mp \psi_{A}}^{\mp 0.5}\left(\omega_{\text {side }}-\omega(\mathrm{y})_{\mathrm{sec}}\right) \mathrm{d} \psi+\right. \\
& \left.\lambda \int_{-0.5}^{0.5}\left(\omega_{\text {side }}-\omega(\mathrm{y})_{\text {prim }}\right) \mathrm{d} \psi\right] \\
\dot{Q}_{L} & =\rho_{\text {av }} \mathrm{h}_{\text {mass }} \mathrm{HW}\left(\omega_{\text {higher }}-\omega_{\text {lower }}\right) i
\end{aligned}
$$

From Fig. (18) the results obtained could be fitted in order to obtain the following equation

$$
\frac{S h}{\operatorname{Re} . \mathrm{Sc}}=0.1726+0.0594 \frac{H}{b_{o}}-0.001714\left(\frac{H}{b_{o}}\right)^{2}
$$

Substituting Sh, Re and Sc numbers in Eq. (20) gives:

$$
h_{\text {mass }} H=u_{o} b_{o} \frac{S h}{\operatorname{Re} S c}
$$

Then:

$$
\begin{aligned}
\dot{Q}_{L}= & \pm u_{o} b_{o} \rho_{a v} h_{g}\left(\omega_{\text {higher }}-\omega_{\text {lower }}\right) \times[0.1726 \\
& \left.+0.0594 \frac{H}{b_{o}}-0.001714\left(\frac{H}{b_{o}}\right)^{2}\right]
\end{aligned}
$$

The positive sign is used for the latent heat added to relatively low humidity ratio and the negative sign is used for the latent heat loss from relatively high humidity ratio.

$$
h_{\text {heat }} \cong \rho C_{p} h_{\text {mass }} \quad \text { (Air-water vapor mixtures) }
$$




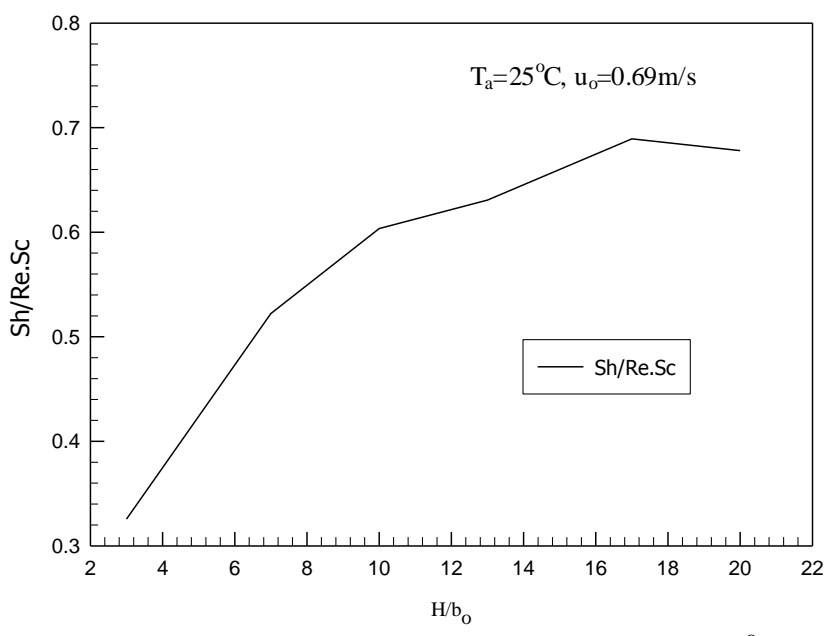

Fig. (18) Variation of Sh/Re Sc with $\mathrm{H} / \mathrm{b}_{\mathrm{o}}$ at $\mathrm{T}_{\mathrm{a}}=25^{\circ} \mathrm{C}$,

$$
\mathrm{u}_{\mathrm{o}}=0.69 \mathrm{~m} / \mathrm{s}
$$

\subsection{Relation between heat transfer Stanton number and mass transfer Stanton number}

As mentioned previously the mass transfer Stanton number is close to the heat transfer Stanton number at different values and as shown in Fig. (19).

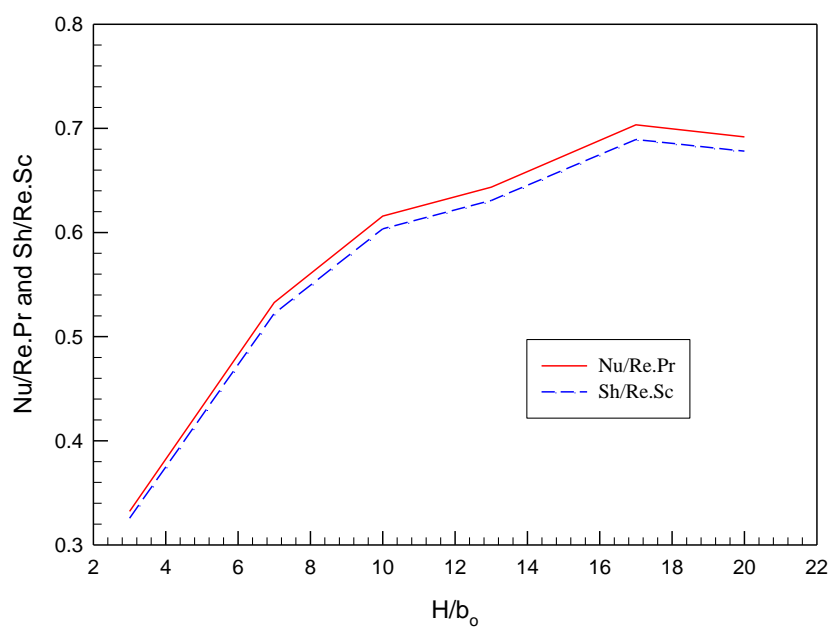

Fig. (19) Relation between Nu/Re .Pr and Sh/Re .Sc at different values $\mathrm{H} / \mathrm{b}_{\mathrm{o}}$

Figure (20) shows the comparison between sensible heat transfer through one air curtain and two air curtains at different ambient temperatures. It is shown that the fridge which equipped with two air curtains had low sensible and latent heat transfer comparing with the fridge equipped with one air curtain. Figure (21) describes the heat and mass transfer through the two air curtains at different values $\mathrm{H} / \mathrm{b}_{\mathrm{o}}$. Therefore, the increase of ambient temperatures and relative humidities lead to increase sensible and latent heat.

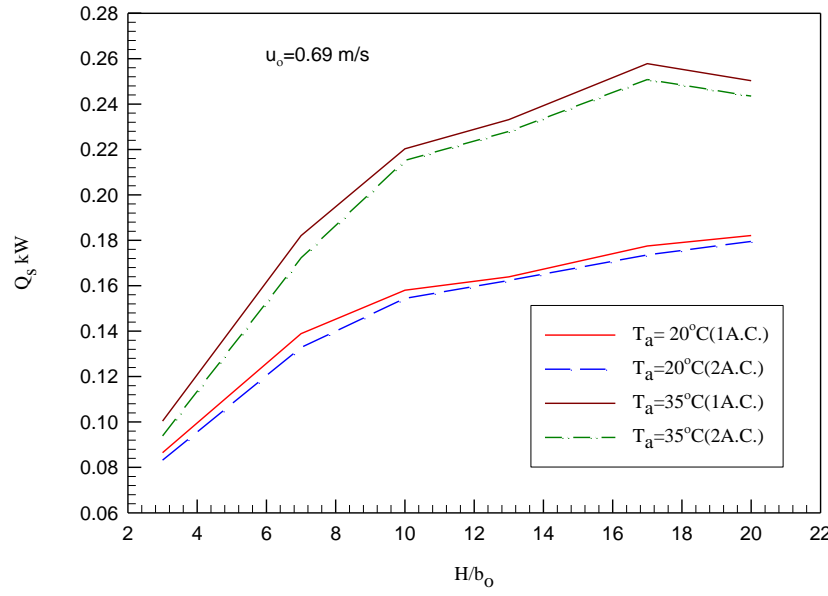

Fig. (20) Comparison of $\mathrm{Q}_{\mathrm{s}}$ of one and two air curtains at different values of $\mathrm{H} / \mathrm{b}_{\mathrm{o}}$

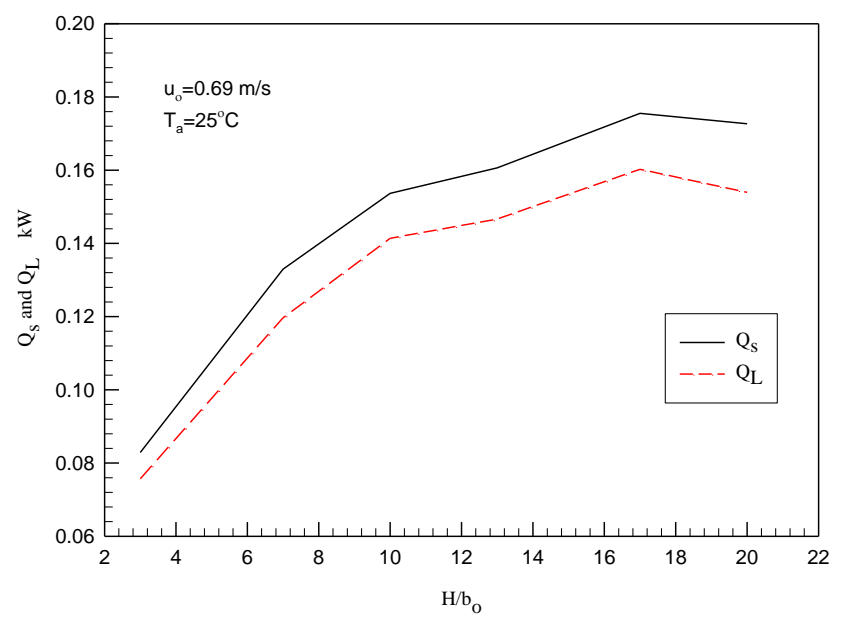

Fig. (21) Relation between $\mathrm{Q}_{\mathrm{s}}$ and $\mathrm{Q}_{\mathrm{L}}$ at different values $\mathrm{H} / \mathrm{b}_{\mathrm{o}}$

The sensible heat transfer obtained from this work is compared with that obtained by G. Verthaeghe [17] and C. Rey [16] and plotted in Figs (22) and (23). The comparison indicates that, the data between the present work and other research were close to each other.

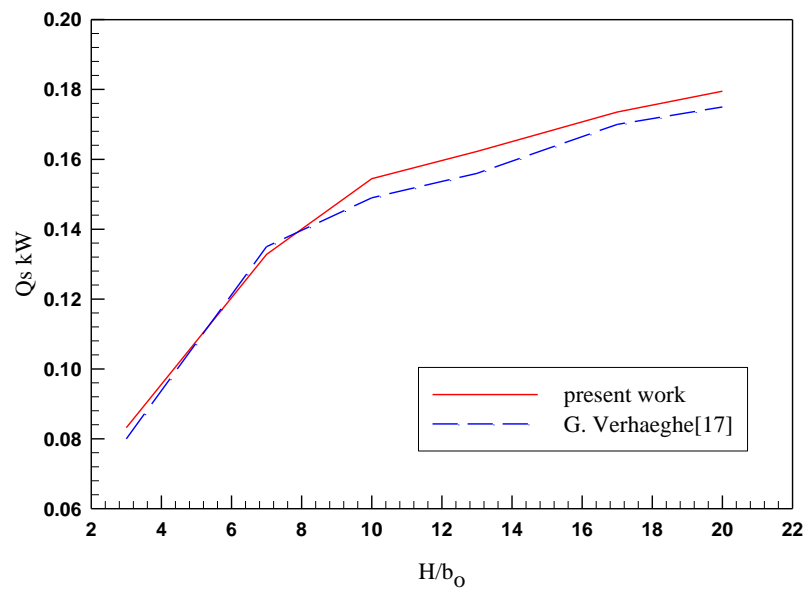

Fig. (22) Variation of $\mathrm{Q}_{\mathrm{s}}$ through one air curtain 


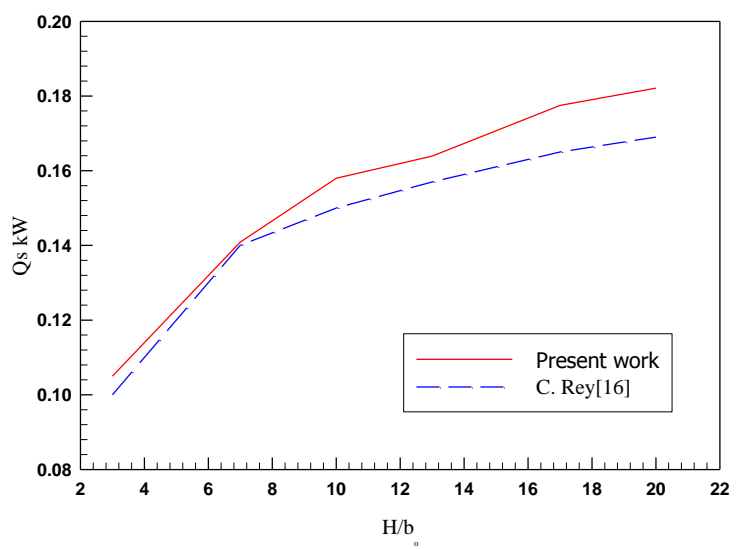

Fig. (23) Variation of $\mathrm{Q}_{\mathrm{s}}$ through two air curtains

\section{Conclusions}

The numerical study on vertical air curtains for multi-deck viewer refrigerated display shows some of the most important factors and parameters that clearly affect the design of the air curtains, its performance and its function to seal a refrigerated space from ambient conditions. From the analysis of the results presented in this study, the following conclusions may be drawn:

1- The air curtain design parameters such as curtain outlet thickness $\left(b_{o}\right)$ and outlet velocity $u_{o}$ have a great effect on the heat and mass transfer rate through the air curtain.

2- The decrease of outlet thickness and velocity of the air curtain increases led to increase of the heat and mass transfer rate.

3- To overcome the increase of the difference between the refrigerated space and ambient conditions, small air curtain thickness and higher outlet velocity are used in the two cases of one air curtain and two air curtains.

4- Using the two air curtains leads to decrease the temperature and humidity ratio inside the fridge and tends also to decrease the power consumption than the case of one air curtain.

5- Using two air curtains into a display cabinet, enhances the performance of the unit is increased when the velocity of outlet air curtain is higher than the velocity of the inlet air curtain.

$\begin{array}{ll}\text { Nomenclature: } \\ \text { Symbol } \\ \text { Quantity } \\ \mathrm{A} & \text { Area, } \mathrm{m}^{2} \\ \mathrm{AC} & \text { Air curtain } \\ \mathrm{Cp} & \text { Specific heat at constant pressure, } \mathrm{kJ} / \mathrm{kg} . \mathrm{K} \\ \mathrm{D} & \text { Diffusion coefficient, } \mathrm{m}^{2} / \mathrm{s} \\ \mathrm{H} & \text { Display cabinet height, } \mathrm{m} \\ \mathrm{h} & \text { Convection heat transfer coefficient, } \mathrm{W} / \mathrm{m}^{2} . \mathrm{K} \\ \mathrm{h}_{\text {mass }} & \text { Mass transfer coefficient, } \mathrm{m} / \mathrm{s} \\ \mathrm{I} & \text { Enthalpy of moisture, } \mathrm{kJ} / \mathrm{kg} \\ \mathrm{k} & \text { Kinetic energy } \\ \mathrm{m}_{\text {conv }} & \text { Rate of mass convection, } \mathrm{kg} / \mathrm{s} \\ \mathrm{Nu} & \text { Nusselt number } \\ \mathrm{P} & \text { Absolute pressure, } \mathrm{N} / \mathrm{m}^{2} \\ \mathrm{Pr} & \text { Prandtl number }\end{array}$

Heat transfer, $\mathrm{kW}$

$\mathrm{R} \quad$ Individual gas constant, $\mathrm{J} / \mathrm{kg} .{ }^{\circ} \mathrm{K}$

$\mathrm{Re} \quad$ Reynolds number

RH Relative humidity

Sc Schmidt Number

Sh Sherwood Number

$\mathrm{St}_{\text {mass }} \quad$ Mass transfer Stanton number, Sh/Re.Sc

S Source of term $\Phi$

$\mathrm{T} \quad$ Temperature, $\mathrm{k}$

$\mathrm{U} \quad$ Velocity vector in $\mathrm{X}$ direction

u Velocity, $\mathrm{m} / \mathrm{s}$

$\mathrm{V} \quad$ Velocity vector in $\mathrm{Y}$ direction

W Width of air curtain, $m$

\section{Greek Letters}

$\begin{array}{ll}\beta & 1 / \mathrm{T} \\ \Gamma & \text { Diffusion coefficient } \\ \varepsilon & \text { Energy dissipation rate } \\ \theta & \text { Dimensionless temperature }=\left(\mathrm{T}-\mathrm{T}_{\mathrm{c}}\right) /\left(\mathrm{T}_{\mathrm{w}}-\mathrm{T}_{\mathrm{c}}\right) \\ \lambda & \text { Switch factor, } 1 \text { or } 0 \\ \mu & \text { Turbulent viscosity, pa s } \\ \rho & \text { Air density, } \mathrm{kg} / \mathrm{m}^{3} \\ \psi & \text { Stream function } \\ \omega & \text { Humidity ratio, } \mathrm{kg}_{\mathrm{v}} / \mathrm{kg}_{\mathrm{a}} \\ \Phi & \text { Dependent variable }\end{array}$

\begin{tabular}{ll}
\multicolumn{2}{l}{ Subscripts } \\
a & Dry air \\
av & Average \\
da & Dry air \\
eff & Effective \\
c & Cold \\
L & Latent heat transfer, kW \\
o & Curtain outlet \\
Prim & Primary \\
s & Sensible heat transfer, kW \\
Sec & Secondary \\
t & Turbulent \\
v & Vapour \\
w & Warm, water vapor
\end{tabular}

\section{References:}

[1] G. Krajewski, "Efficiency of air curtains used for separating smoke free zones in case of fire" $13^{\text {th }}$ conference of internal building performance simulation association chambery, france, august 26-28, proceeding of bs 2013.

[2] G. Hetsroni, "Heat transfer through an air curtain" Ph. D. Thesis, Michigan State University, East Lansing, 1963.

[3] F. C. Hayes, "Heat transfer characteristics of the air curtain: a plane jet subjected to transverse pressure and temperature gradient" Ph. D. Thesis, University of Illinois, Urbana, IL, 1968.

[4] N. Q. Van, "Influence of initial turbulence intensity on heat transfer through a recirculated air curtain" Ph.D. Thesis, University of Missouri-Rolla, Rolla, MO, 1975.

[5] R. H. Howell, P. Adams, "Effects of indoor space conditions on refrigerated display case performance" Final report for ASHRAE. Project No. 596RP, 1991.

[6] G. Cortella, M. Manzan, and G. Comini, "CFD simulation of refrigerated display cabinets" International journal of refrigeration, vol. 24, pp 250-261, 2001. 
[7] HK. Navaz, BS. Henderson, R. Faramarzi, A. Pourmovahed and F. Taugwalder, "Jet entrainment rate in air curtain of open refrigerated display cases" International Journal of Refrigeration, vol. 28, pp 267275, 2005.

[8] KZ. Yu, GL. Ding and TJ Chen, "Modified two-fluid model for air curtains in open vertical display cabinets" International journal of refrigeration, vol. 31, pp 472482, 2008

[9] PD Agaro, G. Cortella and G. Croce, "Two-and threedimensional CFD applied to vertical display cabinets simulation". International Journal of Refrigeration. Vol. 29, pp 178-190, 2006.

[10] Y. T. GE, S. A. Tassou: "Simulation of the performance of single jet air curtains for vertical refrigerated display cabinets" Applied Thermal Engineering vol. 21, pp 201-219, 2001.

[11] P. E. Ramin Faramarzi: "Efficient Display Case Refrigeration" J. Refrigeration, 1999.

[12] A. Yeo, J. A. Reizes, E. Leonardi, and G. Vahl Davis, "Numerical simulation of refrigerated display cabinet", ASHRAE Transactions 2000.

[13] D. B. Spalding, and S. V. Patankar, "A Calculation Procedure for Heat, Mass and Momentum Transfer in Three Dimensional Parabolic Flows" Int. J. Heat \& Mass Transfer, 15, pp. 1787, 1974.

[14] FLUENT user's guide, Version 6. FLUENT, Fluent, Inc; 2003.

[15] Wayne C. Turner and Steve Doty "Energy Management Handbook" $6^{\text {th }}$ edition, Published by the Fairmont Press, Inc., 2006.

[16] M. Pavageau, K. Loubière, A. Koched, F. Aloui, J.C. Elicer-Cortés and C. Rey, "Plane turbulent impinging jets", Turbulence, Heat and Mass Transfer 6, 2009 Begell House, Inc.

[17] G. Verhaeghe, "Study of air curtains used to restrict infiltration into refrigerated rooms". $7^{\text {th }}$ International conference on Heat Transfer, Fluid Mechanics and Thermodynamics, 2010. 